\title{
COMPARISON OF BLOOD PRESSURE MEASUREMENT BY PULSE OXIMETRY AND OSCILLOMETRY TECHNIQUES IN NEONATES
}

\author{
Rajeev Vinayak1, Neelam Grover², Manisha Behal ${ }^{3}$ \\ ${ }^{1}$ Associate Professor, Department of Paediatrics, Maharishi Markandeswar Medical College, Solan, H. P. \\ 2Professor and HOD, Department of Paediatrics, Maharishi Markandeswar Medical College, Solan, H. P. \\ ${ }^{3}$ Associate Professor, Department of Obstetrics \& Gynaecology, Maharishi Markandeswar Medical College, Solan, H. P.
} \begin{abstract}
\section{BACKGROUND}

Blood pressure (BP) measurement is a very important aspect in the management and evaluation of sick and unstable neonates. The aim and objective of this study is to investigate the reliability of the plethysmographic waveform of the pulse oximeter to measure the systolic blood pressure by comparing it with the blood pressure measured by oscillometry method in healthy neonates.
\end{abstract}

\section{MATERIALS AND METHODS}

Non-invasive BP measurements were made using two techniques (pulse oximetry and oscillometry) in 188 neonates. The limit of agreement of statistical method by Bland-Altman was applied, considering oscillometry as the reference method.

\section{RESULTS}

Blood pressures obtained by reappearance of pulse oximetry waveform showed a significantly better correlation (Pearson's correlation coefficient of 0.970 ) with oscillometric measurements in comparison with those obtained by pulse oximetry with disappearance of waveform or by the average of BP values obtained by reappearance and disappearance of pulse oximetry waveform method (Pearson's correlation coefficient of 0.761 and 0.912 , respectively). Additionally, the limits of agreement (mean difference $\pm 2 \mathrm{SD}$ ) between BP values obtained by oscillometry measurements and those obtained by pulse oximetry (reappearance of waveform) were within a clinically acceptable range as opposed to those obtained by the comparison of oscillometric method and pulse oximetry (disappearance of waveform or average of BP obtained by reappearance and disappearance of pulse oximetry waveform method). In case of BP measurement by pulse oximetry method (reappearance of waveform) the average bias was 1.22 $\mathrm{mmHg}$, which was less than the priori criteria of $5 \mathrm{mmHg}$. The confidence limit was $4.0 \mathrm{mmHg}$, which was less than a priori criterion of $5 \mathrm{mmHg}$.

\section{CONCLUSION}

Reappearance of the pulse oximeter plethysmographic waveform is an accurate and reliable way to measure systolic BP noninvasively in stable neonates.

\section{KEYWORDS}

Neonates, Blood Pressure, Pulse Oximetry, Oscillometry.

HOW TO CITE THIS ARTICLE: Vinayak R, Grover N, Behal M. Comparison of blood pressure measurement by pulse oximetry and oscillometry techniques in neonates. J. Evolution Med. Dent. Sci. 2017;6(93):6738-6743, DOI: 10.14260/jemds/2017/1459

\section{BACKGROUND}

Blood pressure (BP) measurement is a very important aspect in the management and evaluation of sick and unstable neonates.1,2 Different methods of recording BP in neonates are available and can be broadly classified as non-invasive and invasive methods.

Traditional flush techniques and methods relying on palpation and auscultation are not sufficiently accurate and just not practical for the small sick neonates. ${ }^{3}$ Auscultatory devices are used infrequently in infants, because the Korotkoff sounds are often unobtainable in $<1$ year of age. ${ }^{4}$ Non-invasive BP taken by palpation of peripheral pulses can be unreliable, as palpation of peripheral pulses can be difficult in newborn. The Doppler method 5 is time consuming and labour intensive, and is thereby not preferred.

'Financial or Other Competing Interest': None.

Submission 10-11-2017, Peer Review 21-11-2017,

Acceptance 24-11-2017, Published 11-12-2017.

Corresponding Author:

Dr. Rajeev Vinayak,

C/o. Satish Behal, House No. 399/A,

Maharani Jhansi Road, Civil Lines,

Ludhiana-141001, Punjab.

E-mail: rsjevx69pro@gmail.com

DOI: $10.14260 /$ jemds $/ 2017 / 1459$
Oscillometry method is still the best possible noninvasive method for measuring $\mathrm{BP}$ and is comparable to invasive BP measured values and has been the standard of care for non-invasive blood pressure assessment in children since early 1980s. ${ }^{6-9}$ The most accurate method of measuring BP is by direct intra-arterial recordings. ${ }^{10}$ Drawbacks are that it is invasive, costly, requires high expertise and frequent calibration and strict sepsis, and cannot be used for normal or less sick patients or in poor resources settings to monitor BP. It can also cause serious vascular side effects to the limb supplied by that artery. ${ }^{11-13}$ Systolic BP (SBP) can also be obtained with a pulse oximetry and inflating a BP cuff around a subject's arm or leg while simultaneously observing the pulse oximetry waveforms. SBP can be found at the point where pulse oximetry waveform abruptly disappears. The reverse method can also be used by fully inflating the cuff and then slowly deflating while observing for the reappearance of pulse waveform. SBP measured by pulse oximetry is characterised by the disappearance and reappearance of the waveform on the monitor screen during cuff inflation, deflation or both. ${ }^{12}$ The few studies using this technique found a good correlation with invasive monitoring. ${ }^{4,14-18}$

Aim of this study is to find out whether this pulse oximetry method (disappearance and/or reappearance of 
plethysmographic waves and/or average of both) can reliably be used for measuring BP of neonates. The study aims to envisage pulse oximetry as comparatively accurate and economical alternative for non-invasive SBP monitoring (in comparison to reference method, i.e. oscillometry method); as many of our hospitals are not equipped with this facility, but are equipped with pulse oximeters.

\section{MATERIALS AND METHODS}

This prospective cross-sectional observational study was done on stable neonates born in Maharishi Markandeshwar Medical College and Hospital (Solan district, Himachal Pradesh, India) over a period of 1 year from 13 July 2016 to 13 July 2017 to compare and statistically analyse blood pressure readings taken by pulse oximetry and oscillometry techniques. Proper approval from the Ethical Committee of our hospital was taken before starting this study. Written informed consent was obtained from the parents/ guardians. Stable neonates of $<28$ days age and $\geq 24 \mathrm{hrs}$. age were recruited for the study. Exclusion criteria were unstable neonates admitted in neonatal intensive care unit for any disease including but not limited only to sepsis, birth asphyxia, hyaline membrane disease, meconium aspiration syndrome, congenital anomalies, baby on intravenous fluids, tube feeding, oxygen supplementation etc.

\section{Blood Pressure Measurements}

$\mathrm{BP}$ was measured according to International recommended guidelines. ${ }^{19-23}$ A BP cuff of appropriate size was tied around right upper arm only. BP cuff was chosen such that the width of cuff is at least $40 \%$ and length is at least $80 \%$ of MAC. Neonates were studied at least for one and one-half hours following their last feeding and when they were in a sleep or quite restful state. Babies were kept in supine position throughout the procedure. BP was measured only if babies were not crying during the whole procedure and before measuring BP for at least 15 minutes. Care was taken that babies were not moving the right upper limb during the whole procedure. BP was measured by the principal investigator only. All BP values were recorded in $\mathrm{mmHg}$.

\section{BP Measurement by Pulse Oximetry}

A properly calibrated mercury sphygmomanometer and neonatal pulse oximetry probe were used for this study. Pulse oximetry probe was applied to the right upper limb. When a stable plethysmographic wave and $\mathrm{SaO} 2$ reading was obtained for 1 minute, the BP cuff was inflated slowly by 2 mmHg increments/ second and point of disappearance of plethysmogram waveform was noted (and labelled under heading SPD- systolic pressure disappearance). Pressure was further raised by $20 \mathrm{mmHg}$ quickly, and then reduced slowly by increments of $2 \mathrm{mmHg} / \mathrm{sec}$. The point of reappearance of plethysmogram waveform was noted (and labelled under the heading SPR- systolic pressure reappearance). BP readings were repeated 3 times at 2 minutes interval (so as to enable adequate blood flow after each recording) and average of these readings were taken for the statistical analysis. The average of readings of SPD $1^{\text {st }}, 2^{\text {nd }}$ and $3^{\text {rd }}$ was labelled as SPD and average of SPR $1^{\text {st, }}, 2^{\text {nd }}$ and 3 rd was labelled SPR. AvgSP (average systolic pressure) $1^{\text {st }}, 2^{\text {nd }}$ and $3^{\text {rd }}$ denote to average of SPR $1^{\text {st }}$ and SPD 1st; of SPR $2^{\text {nd }}$ and SPD $2^{\text {nd; }}$ and of SPR $3^{\text {rd }}$ and SPD $3^{\text {rd }}$ respectively. Average of AvgSP $1^{\text {st }}, 2^{\text {nd }}$ and $3^{\text {rd }}$ was taken and labelled as AvgSP.

\section{BP Measurement by Oscillometry Method}

Oscillometry based sphygmomanometer CardioView-1200 (Cardio Labs Healthcare) was used. BP was measured 15 minutes after BP measured by pulse oximetry method. BP was measured using the right arm with same size cuff applied and by the same person. BP was measured only if the baby was not crying during the whole procedure and before measuring BP for at least 15 minutes. BP was recorded 3 times at interval of 2 minutes each and average of them was taken for statistical analysis. Average of all three readings $\left(1\right.$ st, $2^{\text {nd }}$ and $\left.3^{\text {rd }}\right)$ of mean, systolic and diastolic BP readings were calculated and labelled as Mean BP, Systolic BP and Diastolic BP respectively.

\section{Statistical Analysis}

NCSS 11 software and XLSTAT 2017 software for Windows 10 were used for statistical analysis. Continuous variables were expressed as mean and standard deviation (SD). The Pearson linear regression was used to determine the correlations between BP values using oscillometric method and the method under test. To determine the degree of agreement between the two methods of BP measurement, the technique proposed by Bland and Altman ${ }^{24}$ was used. Before applying limits of agreement technique, the relevant data was tested for normal distribution by Quantile-Quantile plots. Association for the Advancement of Medical Instrumentation (AAMI) in the United States requires that the average difference between the two methods not exceed $5 \mathrm{mmHg}$ with a standard deviation of less than $8 \mathrm{mmHg} .{ }^{25}$ The British Hypertension Society (BHS) protocol requires that a device must give at least $50 \%$ of readings within $5 \mathrm{mmHg}$ and $75 \%$ within $10 \mathrm{mmHg}$ with the two methods (Grade B). ${ }^{26}$ So based on these guidelines, bias and precision estimates of $\pm 5 \mathrm{mmHg}$ and $\pm 5 \mathrm{mmHg}$ respectively were established as priori, as the maximum parameters that would indicate acceptable agreement between methods and precision of the difference.

\section{RESULTS}

This study included a total of 188 subjects. 88 (46.8\%) were born by caesarean and 100 (53.2\%) by vaginal delivery. 38 (20.2\%) subjects had weight between $1.5-2.5 \mathrm{~kg}$ and 150 (79.8\%) had weight > $2.5 \mathrm{~kg} .86(45.7 \%)$ subjects were female and 102 (54.3\%) were male. Detailed characteristics of subjects and BP measurements are as outlined in Table 13. There was a total of 1128 blood pressure measurements, out of which 564 each were made with oscillometric and pulse oximetry methods.

\begin{tabular}{|c|c|c|c|c|c|}
\hline & $\mathbf{N}$ & Minimum & Maximum & Mean & SD \\
\hline Wt. $(\mathrm{kg})$ & 188 & 1.77 & 3.885 & 2.80 & 0.387 \\
\hline L $(\mathrm{cm})$ & 188 & 41 & 53 & 48.39 & 2.181 \\
\hline HC $(\mathrm{cm})$ & 188 & 31.2 & 38 & 34.23 & 1.252 \\
\hline MAC $(\mathrm{cm})$ & 188 & 7.9 & 14 & 10.38 & 0.978 \\
\hline $\begin{array}{c}\text { Age at time of } \\
\text { taking BP } \\
\text { (hrs.) }\end{array}$ & 188 & 24 & 93 & 33.30 & 10.938 \\
\hline $\begin{array}{c}\text { Table 1. Characteristics of the Study Subjects } \\
\text { (Anthropometry and Age at time of BP Measurement) }\end{array}$ \\
\hline
\end{tabular}


$\mathrm{L}=$ Length, $\mathrm{HC}=$ Head circumference, $\mathrm{MAC}=$ Mid arm circumference, $\mathrm{BP}=$ Blood pressure.

\begin{tabular}{|c|c|c|c|c|c|}
\hline $\begin{array}{c}\text { Oscillometry } \\
\text { Method }\end{array}$ & $\mathbf{N}$ & Minimum & Maximum & Mean & SD \\
\hline $\begin{array}{c}\text { Mean BP 1st } \\
\text { (mmHg) }\end{array}$ & 188 & 34 & 60 & 48.15 & 4.710 \\
\hline $\begin{array}{c}\text { Systolic BP 1st } \\
\text { (mmHg) }\end{array}$ & 188 & 56 & 80 & 68.85 & 4.730 \\
\hline $\begin{array}{c}\text { Diastolic BP 1st } \\
\text { (mmHg) }\end{array}$ & 188 & 26 & 52 & 39.64 & 5.199 \\
\hline $\begin{array}{c}\text { Mean BP 2nd } \\
\text { (mmHg) }\end{array}$ & 188 & 36 & 60 & 47.84 & 4.493 \\
\hline $\begin{array}{c}\text { Systolic BP 2nd } \\
\text { (mmHg) }\end{array}$ & 188 & 54 & 78 & 68.87 & 4.168 \\
\hline $\begin{array}{c}\text { Diastolic BP 2nd } \\
\text { (mmHg) }\end{array}$ & 188 & 30 & 50 & 39.13 & 4.574 \\
\hline $\begin{array}{c}\text { Mean BP 3 } \\
\text { (mmHg) }\end{array}$ & 188 & 34 & 60 & 47.50 & 4.410 \\
\hline $\begin{array}{c}\text { Systolic BP 3rd } \\
\text { (mmHg) }\end{array}$ & 188 & 52 & 78 & 68.75 & 4.269 \\
\hline $\begin{array}{c}\text { Diastolic BP 3rd } \\
\text { (mmHg) }\end{array}$ & 188 & 28 & 50 & 38.86 & 4.712 \\
\hline $\begin{array}{c}\text { Mean BP } \\
\text { (mmHg) }\end{array}$ & 188 & 35 & 59 & 47.83 & 4.369 \\
\hline $\begin{array}{c}\text { Systolic BP } \\
\text { (mmHg) }\end{array}$ & 188 & 54 & 75 & 68.82 & 4.167 \\
\hline $\begin{array}{c}\text { Diastolic BP } \\
\text { (mmHg) }\end{array}$ & 188 & 28 & 50 & 39.21 & 4.676 \\
\hline $\begin{array}{c}\text { Table 2. Summary of BP Measured by Oscillometry Method } \\
\text { (Reference Method) }\end{array}$ \\
\hline
\end{tabular}

$\mathrm{BP}=$ Blood pressure, $\mathrm{SD}=$ Standard deviation.

\begin{tabular}{|c|c|c|c|c|c|}
\hline $\begin{array}{c}\text { Pulse } \\
\text { Oximetry } \\
\text { Method }\end{array}$ & $\mathbf{N}$ & Minimum & Maximum & Mean & SD \\
\hline $\begin{array}{l}\text { SPR 1st } \\
\text { (mmHg) }\end{array}$ & 188 & 56 & 80 & 70.51 & 4.278 \\
\hline $\begin{array}{l}\text { SPD 1st } \\
\text { (mmHg) }\end{array}$ & 188 & 64 & 98 & 83.00 & 6.025 \\
\hline $\begin{array}{l}\text { AvgSP } 1 \text { st } \\
\text { (mmHg) }\end{array}$ & 188 & 60 & 87 & 76.67 & 4.847 \\
\hline $\begin{array}{l}\text { SPR 2nd } \\
(\mathrm{mmHg})\end{array}$ & 188 & 54 & 78 & 70.08 & 4.125 \\
\hline $\begin{array}{l}\text { SPD 2nd } \\
(\mathrm{mmHg})\end{array}$ & 188 & 62 & 94 & 83.43 & 5.673 \\
\hline $\begin{array}{l}\text { AvgSP 2nd } \\
\text { (mmHg) }\end{array}$ & 188 & 58 & 84 & 76.76 & 4.397 \\
\hline $\begin{array}{l}\text { SPR 3rd } \\
(\mathrm{mmHg})\end{array}$ & 188 & 54 & 78 & 69.53 & 4.283 \\
\hline $\begin{array}{l}\text { SPD 3 } 3^{\text {rd }} \\
(\mathrm{mmHg})\end{array}$ & 188 & 66 & 94 & 83.81 & 5.577 \\
\hline $\begin{array}{l}\text { AvgSP 3rd } \\
\text { (mmHg) }\end{array}$ & 188 & 60 & 85 & 76.71 & 4.377 \\
\hline SPR (mmHg) & 188 & 54 & 78 & 70.04 & 4.070 \\
\hline SPD (mmHg) & 188 & 64 & 92 & 83.41 & 4.864 \\
\hline $\begin{array}{l}\text { AvgSP } \\
(\mathrm{mmHg})\end{array}$ & 188 & 59 & 84 & 76.71 & 4.188 \\
\hline \multicolumn{6}{|c|}{$\begin{array}{c}\text { Table 3. Summary of BP Measured by Pulse Oximetry } \\
\text { Method (Test Method) }\end{array}$} \\
\hline
\end{tabular}

$\mathrm{BP}=$ Blood pressure, $\mathrm{SPR}=$ Systolic pressure reappearance, $\mathrm{SDP}=$ Systolic pressure disappearance, Avg $\mathrm{SP}=$ Average systolic pressure, $\mathrm{SD}=$ Standard deviation .
Comparison between Systolic Blood Pressure measured by Oscillometry method (BPO) and by Pulse Oximetry method- Reappearance of waveform.

A scatter diagram of the BP values measured with the pulse oximetric method (reappearance of waveform) and Oscillometric (reference) method was made. Most of BP values are seen closely clustered around and also equally distributed above and below the line of equality in a linear fashion. Pearson's correlation coefficient (r) was 0.970 with a significance level of $\mathrm{p}<0.0001$ and $95 \%$ confidence interval (CI) for ' $r$ ' of 0.960 to 0.977 . This means that SBP obtained by pulse oximetry method (reappearance of waveform) is very highly ${ }^{27}$ and positively associated with the SBP measured with oscillometric method. However, the strong correlation does not tell us about agreement between the methods.

Under Bland-Altman statistical analysis while the bias for each paired measurement point varied from -1.33 to 5.33 mmHg (bias is both positive and negative). Across all paired measurements the average difference was $1.22 \mathrm{mmHg}$, the value that would be reported as the bias for this data set. This bias is less than the priori criteria of $5 \mathrm{mmHg}$. The confidence limit is $4.0 \mathrm{mmHg}$, which is less than a priori criterion of 5 mmHg. So, one can conclude that both the accuracy and repeatability of the method is acceptable. Coefficient of repeatability is 3.1144 . It is also noted that 3 data points (1.59\% of total cases) exceed the limits of agreement; two exceed the upper limit and one exceeds the lower limit. On Bland-Altman difference plot, it appears that the BP differences between two methods are scattered around the bias with no obvious pattern, which is validated by the percentage error of $5.81 \%$ and correlation coefficient of $-0.096$.

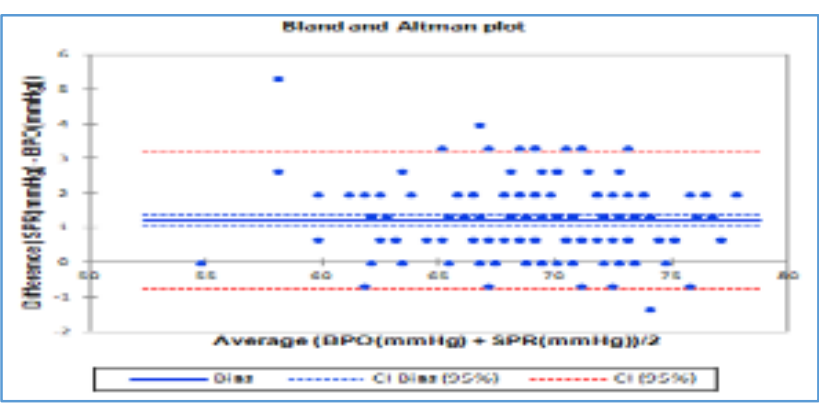

Figure 1. Limits of Agreement (Bland-Altman) Plot of the Comparison of BPO (Systolic BP by Oscillometry) and SPR (Systolic Pressure Reappearance)

CI- Confidence Interval

Comparison between Systolic Blood Pressure measured by Oscillometry method (BPO) and by Pulse Oximetry method- Disappearance of waveform.

The scatter diagram made shows a linear relationship. Pearson's correlation coefficient $(\mathrm{r})$ was 0.761 with a significance level of $\mathrm{p}<0.0001$ and $95 \%$ confidence interval (CI) for ' $r$ ' of 0.693 to 0.815 . It tells that the SBP obtained by pulse oximetry method (disappearance of waveform) is highly ${ }^{27}$ and positively associated with the SBP measured with oscillometric method. However, this correlation does not tell us about agreement between the methods.

Under Bland-Altman statistical analysis while the bias for each paired measurement point varied from 7.33 to 24.67 mmHg (only positive bias seen), across all paired 
measurements the average difference was $14.59 \mathrm{mmHg}$, the value that would be reported as the bias for this data set. The confidence limit is $12.51 \mathrm{mmHg}$. Both bias and confidence are more than the set priori criteria. So, one can conclude that both the accuracy and repeatability of the method are not clinically acceptable. Coefficient of repeatability is 29.267. It is also noted that 5 data points ( $2.66 \%$ of total cases) exceed the limits of agreement; two exceed the upper limit and three exceeds the lower limit. On difference plot it appears that the BP differences between two methods are scattered around the bias with no obvious pattern, which is validated by percentage error of $18.18 \%$ and correlation coefficient of 0.233 .

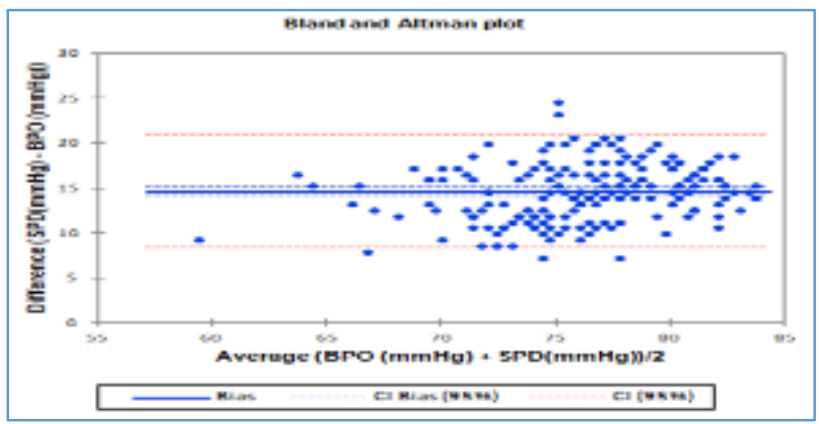

Figure 2. Limits of Agreement (Bland-Altman) Plot of the Comparison of BPO (Systolic BP by Oscillometry) and SPD (Systolic Pressure Disappearance)

\section{CI- Confidence interval.}

Comparison between Systolic Blood Pressure measured by Oscillometry method (BPO) and by Pulse Oximetry method- Average of systolic pressure measured by reappearance and disappearance of pulse oximetry waveform (AvgSP- Average systolic pressure).

The scatter diagram made shows a linear relationship. Pearson's correlation coefficient $(\mathrm{r})$ was 0.912 with a significance level of $\mathrm{p}<0.0001$ and $95 \%$ confidence interval (CI) for ' $r$ ' of 0.884 to 0.933 , which tells that the SBP obtained by pulse oximetry method (reappearance of waveform) is very strongly 27 and positively associated with the SBP measured with oscillometric method. However, the strong correlation does not tell us about agreement between the methods.

Under Bland-Altman statistical analysis while the bias for each paired measurement point varied from 4 to $12 \mathrm{mmHg}$ (only positive bias), across all paired measurements the average difference was $7.89 \mathrm{mmHg}$, the value that would be reported as the bias for this data set. The confidence limit is $6.869 \mathrm{mmHg}$. Both bias and confidence limit are more than the set priori criteria. So, one can conclude that both the accuracy and repeatability of the method are not clinically acceptable.

Coefficient of repeatability is 15.836 . It is also noted that 4 data points $(2.13 \%$ of total cases) exceed the limits of agreement; three exceed the upper limit and one exceeds the lower limit. On Bland-Altman's difference plot it appears that the BP differences between two methods are scattered around the bias with no obvious pattern, which is validated by percentage error of $9.98 \%$ and correlation coefficient for difference plot of 0.013 .

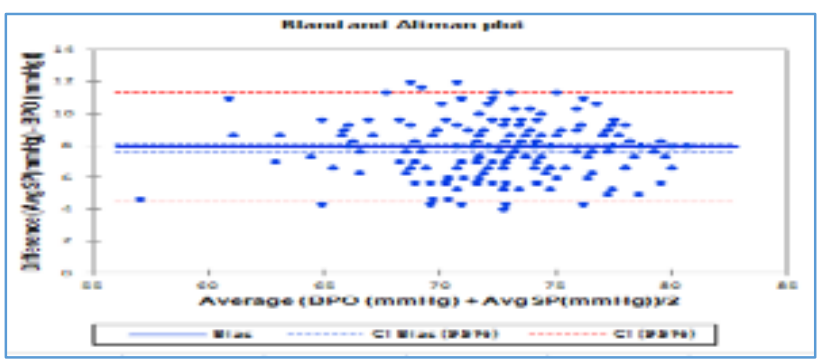

Figure 3. Limits of Agreement (Bland-Altman) Plot of the Comparison of BPO (Systolic BP by Oscillometry) and AvgSP (Average Systolic Pressure)

CI- Confidence interval.

\section{DISCUSSION}

The present study was carried out to evaluate the usefulness of pulse oximeter as a tool to record BP in neonates. Pulse oximetry is not only used to record oxygen saturation in blood, but also the heart rate of newborns. Pulse oximetry is an important, comparatively cheap and easily available equipment in all hospitals; hence, I have used its availability as a tool to record BP in neonates. Since first report in 1987,28 it has been seen in various studies that pulse oximetry detects blood pressure values very close to those obtained when using Doppler ultrasound.11,14-15,29-30

In our study, we found the reappearance of the pulse oximeter plethysmographic waveform during BP cuff deflation to be a useful method of non-invasively measuring $\mathrm{BP}$ in normal neonates. Under Bland-Altman statistical analysis, the average bias is $1.22 \mathrm{mmHg}$ and the confidence limit is $4.0 \mathrm{mmHg}$, which is less than a priori criterion of 5 mmHg. While considering BP at disappearance of waveform and BP value that is average of BP measured by disappearance and reappearance of waveform, the average bias is 14.59 and $7.89 \mathrm{mmHg}$ respectively and the confidence limit is 12.51 and $6.869 \mathrm{mmHg}$, respectively. Both bias and confidence limits are more than the set priori criteria. So one can conclude that both the accuracy and repeatability of the method of measuring BP by reappearance of waveform by pulse oximetry is acceptable and BP measured by disappearance of waveform or by taking average of both is not clinically acceptable. This is not surprising, because it has been shown that less blood flow is required to restart the pulse oximeter tracing during blood pressure cuff deflation than is needed to maintain the tracing during BP cuff inflation. ${ }^{31}$

Movius AJ et al 14 and Avadhesh 0 et al ${ }^{17}$ found that SBP correlates better with pulse oximetric $\mathrm{BP}$ recordings taken at reappearance of plethysmogram, while slowly deflating the BP cuff. In study by Langbaum $\mathrm{M}$ et al,11 difference between BP measured by appearance and disappearance of pulse oximetry waveform was found to be insignificant and both were significantly in agreement with intra-arterial method. Study by Khalili GR et al $^{32}$ found BP measured during inflation of BP cuff to be in best agreement with SBP obtained by conventional method. But unlike our study, they used inflation increments and deflation decrements of $2.5 \mathrm{mmHg}$ 
with a pause period of 2 seconds after each increment or decrement to observe the plethysmographic display.

Pulse oximetry is a comparatively accurate alternative for non-invasive BP monitoring, especially in poorly equipped hospitals or poor patients who are not able to afford costly tertiary healthcare. We conclude that using the reappearance of the pulse oximeter plethysmographic waveform is an accurate and reliable way to measure SBP non-invasively in stable neonates. Further studies may be needed to confirm its accuracy in the hypotensive and hypertensive ranges and sick neonates.

\section{Study Limitations}

Measurements were not alternated (pulse-oximetric/ oscillometric) or randomised, but rather performed in fixed order- 3 pulse-oximetric followed by 3 oscillometric, thus introducing a bias relating to the effect of measurement on the measured values.

\section{CONCLUSION}

Reappearance of the pulse oximeter plethysmographic waveform is an accurate and reliable way to measure systolic BP non-invasively in stable neonates.

\section{ACKNOWLEDGEMENTS}

We thank the neonatal intensive care nurses for their invaluable help in assisting with this project.

\section{REFERENCES}

[1] Rennie JM. Cerebral blood flow velocity variability after cardiovascular support in premature babies. Arch Dis Child 1989;64(7 Spec No):897-901.

[2] Nuntnarumit P, Yang W, Bada-Ellzey HS. Blood pressure measurements in the newborn. Clin Perinatol 1999;26(4):981-6.

[3] Virnig NL, Reynolds JW. Reliability of flush blood pressure measurements in the sick newborn infant. J Pediatr 1974;84(4):594-8.

[4] de Swiet M, Dillon MJ, Littler W, et al. Measurement of blood pressure in children. Recommendations of a working party of the British hypertension society. BMJ 1989;299(6697):497.

[5] Weindling AM. Blood pressure monitoring in the newborn. Arch Dis Child 1989;64(4 Spec no):444-7.

[6] Colan SD, Fujji A, Borrow KM, et al. Noninvasive determination of systolic, diastolic and end systolic blood pressure in neonates, infants and young children: comparison with central aortic pressure measurements. Am J Cardiol 1983;52(7):867-70.

[7] Engle WD. Blood pressure in the very low birth weight neonate. Early Hum Dev 2001;62(2):97-130.

[8] Diprose GK, Evans DH, Archer LN, et al. Dinamap fails to detect hypotension in very low birthweight infants. Arch Dis Child 1986;61(8):771-3.

[9] Park MK, Menard SM. Accuracy of blood pressure measurement by the Dinamap monitor in infants and children. Pediatrics 1987;79(6):907-14.

[10] Butt WW, Whyte HW. Blood pressure monitoring in neonates: comparison of umbilical and peripheral artery catheter measurements. J Pediatr 1984;105(4):630-2.
[11] Langbaum M, Eyal FG. A practical and reliable method of measuring blood pressure in the neonate by pulse oximetry. J Pediatr 1994;125(4):591-5.

[12] Jones DW, Appel LJ, Sheps SG, et al. Measuring blood pressure accurately: new and persistent challenges. JAMA 2003;289(8):1027-30.

[13] Dasgupta SJ, Gill AB. Hypotension in the very low birthweight infant: the old, the new, and the uncertain. Arch Dis Child Fetal Neonatal Ed 2003;88(6):F450-4.

[14] Movius AJ, Bratton SL, Sorensen GK. Use of pulse oximetry for blood pressure measurement after cardiac surgery. Arch Dis Child 1998;78(5):457-60.

[15] Chawla R, Kumarvel V, Girdhar KK, et al. Can pulse oximetry be used to measure systolic blood pressure? Anesth Analg 1992;74(2):196-200.

[16] Talke P, Nicholas RJ, Traber DL. Does measurement of systolic blood pressure with a pulse oximeter correlate with conventional methods? J Clin Monit 1990;6(1):5-9.

[17] Avadhesh 0, Gupta G, Nair MNG. Can pulse-oximetry be used to record blood pressure in neonates accurately? J of Neonatology 2003;17(4).

[18] Sanghvi KP, Steer P. Non-invasive blood pressure measurement in neonates using pulse oximetry and sphygmomanometry. Indian Pediatr 1998;35(10):1001-4.

[19] The fourth report on the Diagnosis, Evaluation, and Treatment of High Blood Pressure in Children and Adolescents. U.S. Department of Health and Human Services. National Institutes of Health. National Heart, Lung, and Blood Institute. NIH Publication No. 055267. Originally printed 1996 Sep (96-3790): Revised May 2005.

[20] Nwankwo MU, Lorenz JM, Gardiner JC. A standard protocol for blood pressure measurement in the newborn. Pediatrics 1997;99(6):E10.

[21] Dinamap PRO 1000V3 Monitor Operation Manual, Revision 2012093-003 A 2003. Milwaukee, Wis: GE Medical Systems Information Technologies; 2003.

[22] Beevers G, Lip GY, O'Brien E. Blood pressure measurement: Part II-conventional sphygmomanometry: technique of auscultatory blood pressure measurement. BMJ 2001;322(7293):1043-7.

[23] O'Brien E, Asmar R, Beilin L, et al. European society of hypertension recommendations for conventional, ambulatory and home blood pressure measurement. J Hypertens 2003;21(5):821-48.

[24] Bland JM, Altman DG. Measuring agreement in method comparison studies. Stat Methods Med Res 1999;8(2):135-60.

[25] Association for the Advancement of Medical Instrumentation, Association for the Advancement of Medical Instrumentation. American National Standard ANSI/AAMI SP10: 2002. Manual, Electronic, or Automated Sphygmomanometers. AAMI: Arlington, VA. 2003.

[26] O'Brien E, Petrie J, Littler W, et al. The British hypertension society protocol for the evaluation of automated and semi-automated blood pressure measuring devices with special reference to ambulatory systems. J Hypertens 1990;8(7):607-19. 
[27] Hinkle DE, Wiersma W, Jurs SG. Applied statistics for the behavioral sciences. $5^{\text {th }}$ edn. Boston: Houghton Mifflin; 2003.

[28] Wallace CT, Baker JD, Alpert CC, et al. Comparison of blood pressure measurement by doppler and by pulse oximetry techniques. Anesth Analg 1987;66(10): 1018-9.

[29] Northern Neonatal Nursing Initiative. Systolic blood pressure in babies of less than 32 weeks gestation in the first year of life. Arch Dis Child Fetal Neonatal Ed 1999;80(1):F38-42.
[30] Ribeiro MA, Fiori HH, Luz JH, et al. Comparison of noninvasive techniques to measure blood pressure in newborns. J Pediatr (Rio J) 2011;87(1):57-62.

[31] Lawson D, Norley I, Korbon G, et al. Blood flow limits and pulse oximeter signal detection. Anesthesiology 1987;67(4):599-603.

[32] Khalili GR, Saghaei M, Abedini M. Blood pressure measurement by pulse oxymetric method and comparison with conventional technique. Acta Anaesthesiol Sin 2002;40(1):3-7. 